\title{
Exercise ventilatory inefficiency in mild to end-stage COPD
}

\author{
J. Alberto Neder ${ }^{1,2}$, Flavio F. Arbex², Maria Clara N. Alencar², \\ Conor D.J. O'Donnell', Julia Cory ${ }^{1}$, Kathy A. Webb ${ }^{1}$ and Denis E. O'Donnell ${ }^{1}$ \\ Affiliations: ${ }^{1}$ Respiratory Investigation Unit and Laboratory of Clinical Exercise Physiology, Queen's University \\ and Kingston General Hospital, Kingston, ON, Canada. \\ ${ }^{2}$ Clinical Exercise Physiology Unit (SEFICE), Division of Respirology, Federal University of Sao Paulo, Sao Paulo, \\ Brazil.
}

Correspondence: Denis E. O'Donnell, 102 Stuart Street, Kingston, K7L 2V6, ON, Canada.

E-mail: odonneldqueensu.ca

ABSTRACT Ventilatory inefficiency during exercise is a key pathophysiological feature of chronic obstructive pulmonary disease. Currently, it is unknown how this physiological marker relates to clinically relevant outcomes as resting ventilatory impairment progresses across disease stages.

Slope and intercept of the linear region of the ventilation-carbon dioxide output relationship and the ratio between these variables, at the lowest point (nadir), were contrasted in 316 patients with Global Initiative for Chronic Obstructive Lung Disease (GOLD) stages 1-4 (forced expiratory volume in $1 \mathrm{~s}$, ranging from $148 \%$ pred to $12 \%$ pred) and 69 aged- and gender-matched controls,

Compared to controls, slope and intercept were higher in GOLD stages 1 and 2, leading to higher nadirs $(\mathrm{p}<0.05)$. Despite even larger intercepts in GOLD stages 3 and 4, slopes diminished as disease evolved (from mean \pm SD $35 \pm 6$ in GOLD stage 1 to $24 \pm 5$ in GOLD stage $3, \mathrm{p}<0.05$ ). As a result, there were no significant differences in nadirs among patient groups. Higher intercepts, across all stages $(\mathrm{p}<0.01)$, and to a lesser extent lower slopes in GOLD stages $2-4 \quad(\mathrm{p}<0.05)$, were related to greater mechanical constraints, worsening pulmonary gas exchange, higher dyspnoea scores, and poorer exercise capacity.

Increases in the ventilation intercept best indicate the progression of exercise ventilatory inefficiency across the whole spectrum of chronic obstructive pulmonary disease severity.

@ERSpublications

Exercise ventilatory inefficiency relates to dyspnoea and exercise intolerance across whole COPD severity spectrum http://ow.ly/CpWLj 


\section{Introduction}

Minute ventilation $\left(V^{\prime} \mathrm{E}\right)$ during moderate exercise (i.e. in the absence of metabolic acidosis) is tightly coupled to the rate of carbon dioxide production, washed-out by the lungs $\left(V^{\prime} \mathrm{CO}_{2}\right)[1,2]$. In fact, $V^{\prime} \mathrm{E}$ increases almost exactly enough to keep arterial carbon dioxide tension $\left(\mathrm{PaCO}_{2}\right)$ constant, despite increasing $V^{\prime}$ E $[3,4]$. As cogently pointed out by WhIPP ANDWARD [1] and WhIPP [5], this can occur only if there is a proportional matching between two decreasing ratios: dead space $(V D)$ to tidal volume $(V T)$ and $V^{\prime} \mathrm{E} / V^{\prime} \mathrm{CO}_{2}$. The hyperbolic $V^{\prime} \mathrm{E} / V^{\prime} \mathrm{CO}_{2}$ behaviour towards its lowest value (nadir) is a necessary consequence of a positive y-intercept in the linear $V^{\prime} \mathrm{E}-V^{\prime} \mathrm{CO}_{2}$ relationship under isocapnic conditions [5]. In cardio-respiratory disease, the $V^{\prime} \mathrm{E}-V^{\prime} \mathrm{CO}_{2}$ slope and $V^{\prime} \mathrm{E} / V^{\prime} \mathrm{CO}_{2}$ nadir increase (i.e. ventilatory inefficiency worsens) reflecting a higher $V \mathrm{D} / V \mathrm{~T}$ and/or a lower $\mathrm{PaCO}_{2}$ set-point 6; provided the ventilatory response is not constrained by abnormal lung mechanics. This explains why these findings may be useful to assess disease severity when mechanical abnormalities do not play a major role in limiting exercise capacity, e.g. heart failure and pulmonary arterial hypertension $[7,8]$.

However, a more complex scenario emerges in a highly-heterogeneous condition, such as chronic obstructive pulmonary disease (COPD). The $V^{\prime} \mathrm{E}-V^{\prime} \mathrm{CO}_{2}$ relationship has been used to assess disease progression [9-11], identify the presence of comorbidities [12-15] and to evaluate the effect of therapeutic interventions [16-19] in such patients. This is physiologically justified by evidence of COPD progression being associated with increased ventilation-perfusion mismatch and lower exercise tolerance, leading to poorer ventilatory efficiency [20]. However, concomitant increases in $\mathrm{PaCO}_{2}$ and mechanical constraints are expected to flatten the ventilatory response in these patients, i.e. the $V^{\prime} \mathrm{E}-V^{\prime} \mathrm{CO}_{2}$ slope might, paradoxically, decrease as the disease evolves and mechanical abnormalities worsen (fig. 1a) [22-25]. The $V^{\prime} \mathrm{E} / V^{\prime} \mathrm{CO}_{2}$ nadir may also not accurately reflect the extent of ventilatory inefficiency as slope and intercept may change in opposite directions to potentially cancel each other out, i.e. the nadir would become stable despite COPD progression (fig. 1b) [5, 24, 25]. As a further complicating issue, a high nadir may be a result of too short a test, in which the decreasing profile may be "amputated" by premature exercise cessation in unfit and severely limited patients (fig. 1b) $[6,26]$. Consequently, it remains unknown how best to express ventilatory inefficiency as the mechanical constraints, gas exchange disturbances and exercise intolerance worsen from the mild to the end-stage of COPD.

The primary aim of this study, therefore, was to provide a comprehensive frame of reference to interpret the measures of ventilatory inefficiency as COPD evolves. Secondly, we wished to examine associations between those measures with ventilatory capacity and patient centred outcomes (dyspnoea and exercise tolerance), across the continuum of COPD severity. We reasoned that these data would provide a more sound physiological background to clinically interpret the relationship in this patient population [9-19].

\section{Methods}

\section{Subjects}

This study involved a retrospective analysis of incremental cycle cardiopulmonary exercise studies performed as screening for several ethically-approved research studies on COPD at the Respiratory
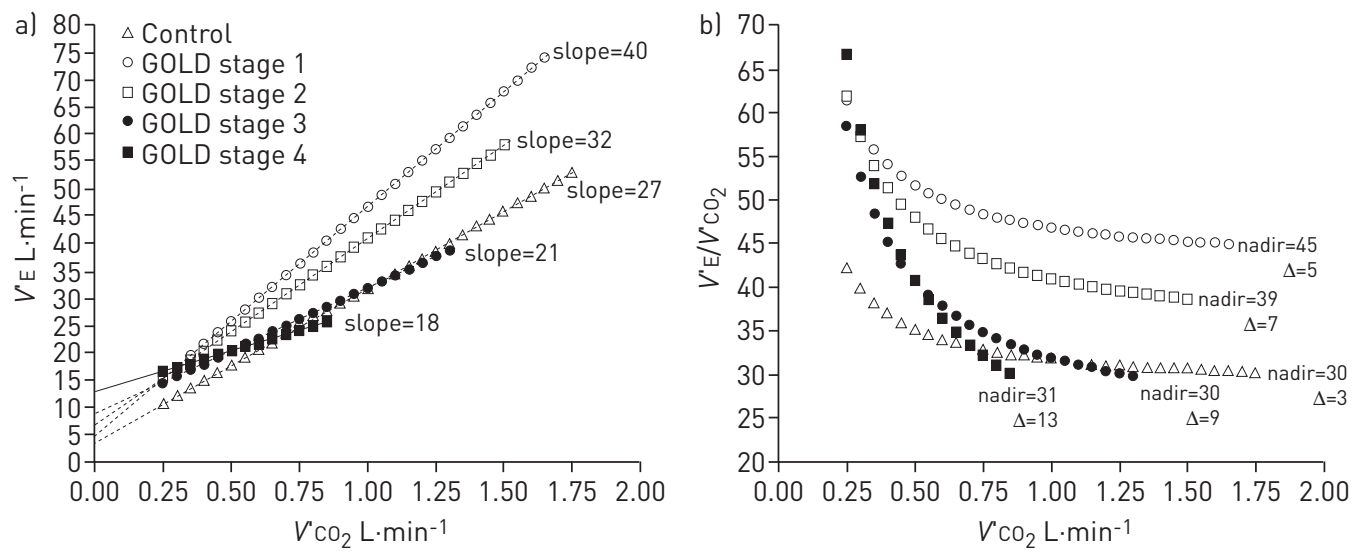

FIGURE 1 Schematic representation of the linear minute ventilation $\left(V^{\prime} \mathrm{E}\right)$ carbon dioxide production ( $\left.V^{\prime} \mathrm{CO}_{2}\right)$ relationship, assuming that the slope decreases and the intercept increases as chronic obstructive pulmonary disease progresses (a). Slopes are based on previous reports [9-12] and intercepts are biologically plausible values, starting from a normal reference value of $\sim 3 \mathrm{~L} \cdot \mathrm{min}^{-1}[21]$. b) The resulting effects on $V^{\prime} \mathrm{E} / V^{\prime} \mathrm{CO}_{2}$ nadir and on the nadir-slope difference $(\Delta)$. GOLD: Global Initiative for Chronic Obstructive Lung Disease. 
Investigation Unit, Queen's University and Kingston General Hospital (Kingston, ON, Canada). The Queen's University and Affiliated Teaching Hospitals Research Ethics Board approved the use of these anonymous data sets and waived the need for patient informed consent (DMED-1659-13). Patients had a well-established diagnosis of COPD [27], with no evidence of asthma or any other lung disease. Patients were required to have been free of any exacerbation in the preceding 6 weeks. Controls had no major respiratory, cardiovascular or metabolic diseases that could interfere with the study's results. Lack of orthopaedic, neuromuscular, cardiac and metabolic conditions, which could preclude the subject from safely undertaking incremental, exercise tests, were part of the inclusion criteria of the study.

\section{Procedures}

Lung Function Tests

Spirometry (including inspiratory capacity (IC) measurements), body plethysmography (residual volume (RV), total lung capacity (TLC), and airways resistance (Raw)), and diffusing capacity of the lung for carbon monoxide (DLCO) were performed using automated testing equipment (2130 spirometer with 6200 Autobox DL or V6200 Autobox; SensorMedics, Yorba Linda, CA, USA). All short-acting and long-acting bronchodilators were withdrawn for at least $4 \mathrm{~h}$ and $12-24 \mathrm{~h}$, respectively. As patients had taken part in studies with different bronchodilators, spirometric Global Initiative for Chronic Obstructive Lung Disease (GOLD) stages were defined according to pre-bronchodilator forced expiratory volume in $1 \mathrm{~s}$ (FEV1) [27].

\section{Exercise Tests}

Symptom-limited, incremental, exercise testing was performed on an electronically braked cycle ergometer using the Vmax229d Cardiopulmonary Exercise Testing System (SensorMedics). The rate of work rate increment was individually selected according to reported exercise tolerance and resting functional impairment $\left(5-10 \mathrm{~W} \cdot \mathrm{min}^{-1}\right.$ in GOLD stages 3 and $4,10-15 \mathrm{~W} \cdot \mathrm{min}^{-1}$ in GOLD stages 1 and 2, and 5-20 $\mathrm{W} \cdot \mathrm{min}^{-1}$ in healthy subjects). $V^{\prime} \mathrm{E}\left(\mathrm{L} \cdot \mathrm{min}^{-1}\right), V^{\prime} \mathrm{CO}_{2}\left(\mathrm{~L} \cdot \mathrm{min}^{-1}\right)$, oxygen uptake $\left(V^{\prime} \mathrm{O}_{2}\right)\left(\mathrm{L} \cdot \mathrm{min}^{-1}\right)$, end-tidal carbon dioxide tension $\left(\mathrm{PETCO}_{2}\right)(\mathrm{mmHg})$, respiratory frequency $(f \mathrm{R})$ (breaths. $\left.\mathrm{min}^{-1}\right)$ and $V \mathrm{~T}(\mathrm{~L})$ were averaged at $30 \mathrm{~s}$ intervals. Arterial oxygen saturation was measured by pulse oximetry $\left(\mathrm{SpO}_{2}\right)(\%)$ noninvasively. Breathlessness was rated according to the 10-point Borg category-ratio scale [28]. The linear phase of the $V^{\prime} \mathrm{E}-V^{\prime} \mathrm{CO}_{2}$ relationship was determined in the $V^{\prime} \mathrm{E}-V^{\prime} \mathrm{CO}_{2}$ plot $\left(V^{\prime} \mathrm{E}\right.$ is y-axis and $V^{\prime} \mathrm{CO}_{2}$ is $\mathrm{X}$-axis). Linear regression was then applied to these data points $[21,26]$. Nadir and the peak $V^{\prime} \mathrm{E} / V^{\prime} \mathrm{CO}_{2}$ ratio $\left(V^{\prime} \mathrm{E} / V^{\prime} \mathrm{CO}_{2}\right.$ peak) were the lowest and the last 30-s average data point, respectively [21]. End-inspiratory lung volume (EILV) (L) was calculated as end-expiratory lung volume (EELV), taken from IC, plus VT and related to TLC [20]. Peak $V^{\prime}$ E response ( $V^{\prime}$ Epeak) was also expressed relative to estimated maximal voluntary ventilation $(\mathrm{MVV})\left(\mathrm{L} \cdot \mathrm{min}^{-1}\right)$, which was equal to $\mathrm{FEV} 1 \times 35$. Due to the expected differences in maximal exercise capacity among the COPD stages, EILV/TLC $(\times 100)$ and dyspnoea scores were corrected for the $V^{\prime}$ Epeak. For the same reasons $V^{\prime}$ Epeak and MVV were corrected for the peak metabolic stress $\left(V^{\prime} \mathrm{O}_{2}\right.$ peak $)$.

\section{Statistical Analysis}

Values are reported as means \pm SD, unless otherwise stated. A p-value $<0.05$ was considered significant in all analyses. Intraclass correlation coefficients determined the level of between-investigator agreement in the calculation of slope and intercept. Comparisons across subgroups were performed using ANOVA with post hoc testing of significant variables carried out using t-tests with Bonferroni adjustment for multiple comparisons. Chi-squared analysis tested the association between categorical variables. Pearson's R tested the correlation between continuous variables.

\section{Results}

\section{Subject characteristics}

316 patients distributed across all GOLD stages and 69 controls were evaluated. Patients and controls were well matched for age $(67.7 \pm 6.2$ years versus $68.4 \pm 7.2$ years), sex (179 (56.6\%) out of 316 versus 37 (53.7\%) out of 69 males) and body mass index $\left(26.9 \pm 4.8 \mathrm{~kg} \cdot \mathrm{m}^{-2}\right.$ versus $\left.26.0 \pm 3.1 \mathrm{~kg} \cdot \mathrm{m}^{-2}\right)(\mathrm{p}>0.05)$. Table 1 shows the expected decreases in IC, IC/TLC and DLCO and increases in RV, TLC and Raw as airway obstruction gradually worsened from GOLD stage 1 to $4(\mathrm{p}<0.01)$.

\section{Physiological and perceptual responses according to GOLD stages}

Peak exercise capacity was progressively reduced from healthy controls to very-severe COPD (table 2 and fig. 2a). These findings were associated with gradual worsening of the mechanical ventilatory constraints (fig. $2 \mathrm{~b}$ and c). Peak-rest changes in $\mathrm{PETCO}_{2}$ increased (fig. 2d) and $\mathrm{SpO}_{2}$ decreased (fig. 2e) as airway obstruction increased. Peak-rest changes in $\mathrm{PETCO}_{2}$ did not correlate with $f \mathrm{R}$ either in controls or patients $(\mathrm{r}=0.04$ and 0.12 , respectively, $\mathrm{p}>0.05)$. Ventilation-corrected dyspnoea scores increased from GOLD stage 1 to 4 (fig. 2f). Exercise test duration was lower in GOLD stages 4 and 3 when compared to GOLD stages 2 and 1 , and controls (table 2) $(\mathrm{p}<0.05)$. 
TABLE 1 Selected resting functional variables in healthy controls and chronic obstructive pulmonary disease patients separated by Global Initiative for Chronic Obstructive Lung Disease (GOLD)

\begin{tabular}{lccccc} 
& Controls & \multicolumn{5}{c}{ GOLD stage } \\
\cline { 3 - 6 } & & $\mathbf{1}$ & $\mathbf{2}$ & $\mathbf{3}$ & $\mathbf{4}$ \\
\hline Subjects & 69 & 81 & 112 & 84 & 39 \\
FEV $\%$ predicted & $111.4 \pm 13.7$ & $94.3 \pm 13.5^{*, \#}$ & $62.4 \pm 9.4^{*, \#}$ & $39.7 \pm 6.1^{*, \#}$ & $23.6 \pm 3.5^{*, \#}$ \\
FEV $/$ FVC & $0.76 \pm 0.04$ & $0.61 \pm 0.06^{*, \#}$ & $0.50 \pm 0.09^{*, \#}$ & $0.39 \pm 0.07^{*, \#}$ & $0.32 \pm 0.07^{*, \#}$ \\
IC \% predicted & $108.4 \pm 15.4$ & $106.1 \pm 21.9^{\#}$ & $88.5 \pm 18.2^{*, \#}$ & $73.7 \pm 17.5^{*, \#}$ & $53.0 \pm 11.5^{*, \#}$ \\
IC/TLC & $0.48 \pm 0.08$ & $0.45 \pm 0.07^{\#}$ & $0.37 \pm 0.08^{*, \#}$ & $0.29 \pm 0.07^{*, \#}$ & $0.19 \pm 0.05^{*, \#}$ \\
TLC \% predicted & $103.1 \pm 13.4$ & $105.4 \pm 14.0$ & $109.5 \pm 14.0^{*, \#}$ & $116.9 \pm 18.5^{*, \#}$ & $130.1 \pm 19.8^{*, \#}$ \\
RV \% predicted & $88.4 \pm 15.6$ & $103.5 \pm 22.1^{*, \#}$ & $137.7 \pm 32.0^{*, \#}$ & $184.6 \pm 47.4^{*, \#}$ & $255.9 \pm 65.9^{*, \#}$ \\
Raw CmH $_{2} \mathbf{O}^{-1} \mathbf{L}^{-1} \cdot \mathbf{s}^{-1}$ & $5.18 \pm 1.81$ & $8.82 \pm 2.78^{*, \#}$ & $16.70 \pm 7.15^{*, \#}$ & $27.04 \pm 10.60^{*, \#}$ & $43.81 \pm 15.29^{*, \#}$ \\
DLCo \% predicted & $102.1 \pm 20.7$ & $81.5 \pm 22.3^{*, \#}$ & $68.0 \pm 21.5^{*, \#}$ & $57.6 \pm 19.0^{*, \#}$ & $45.9 \pm 17.2^{*, \#}$
\end{tabular}

Data are presented as $\mathrm{n}$ or mean $\pm \mathrm{SD}$. FEV1: forced expiratory volume in $1 \mathrm{~s}$; FVC: forced vital capacity; IC: inspiratory capacity; TLC: total lung capacity; RV: residual volume; Raw: airways resistance; DLCo: diffusing capacity of the lung for carbon monoxide. *: $p<0.05$ versus controls; ${ }^{\#}$ : $p<0.05$ versus other GOLD stages.

\section{Ventilatory inefficiency across GOLD stages}

Between observers, the intraclass correlation coefficients for intercept and slope estimation were excellent $(r=0.98$ and 0.97 , respectively, $\mathrm{p}<0.01)$ with $\mathrm{r}^{2}$ values for the relationship ranging from 0.92 to 0.99 . Compared to controls, all patient groups had higher intercepts; in contrast, slopes were increased in GOLD stages 1 and 2, similar in GOLD stage 3 and lower in GOLD stage 4 (actual values being: $3.0 \pm 1.1 \mathrm{~L} \cdot \mathrm{min}^{-1}$, $4.2 \pm 1.3 \mathrm{~L} \cdot \mathrm{min}^{-1}, 5.8 \pm 2.6 \mathrm{~L} \cdot \mathrm{min}^{-1}, 7.2 \pm 2.8 \mathrm{~L} \cdot \mathrm{min}^{-1}$ and $8.3 \pm 3.0 \mathrm{~L} \cdot \mathrm{min}^{-1}$ for the intercepts and $27 \pm 3,35 \pm 6$, $31 \pm 5,27 \pm 5$ and $24 \pm 5$ for the slopes, respectively) (fig. 3 shows representative patients and fig. $4 \mathrm{a}$ and $\mathrm{b}$ show the mean data).

There was a negative correlation between intercept and slope across the patient groups (fig. 5a). Intragroup prevalence of high intercepts and slopes ( $>95 \%$ upper confidence limit observed in controls, $5 \mathrm{~L} \cdot \mathrm{min}^{-1}$ and 32, respectively) varied in opposite directions in GOLD stages 1-4 (fig. 6). These results were consistent with those found in a between sex, comparative analysis, i.e. the relative proportion of high intercepts and slopes in each stage did not differ in males versus females $(\mathrm{p}>0.05)$.

TABLE 2 Selected peak exercise variables in healthy controls and chronic obstructive pulmonary disease patients separated by Global Initiative in Chronic Obstructive Lung Disease (GOLD)

\begin{tabular}{|c|c|c|c|c|c|}
\hline & \multirow[t]{2}{*}{ Controls } & \multicolumn{4}{|c|}{ GOLD stage } \\
\hline & & 1 & 2 & 3 & 4 \\
\hline Subjects & 69 & 81 & 112 & 84 & 39 \\
\hline Time min & $10.1 \pm 2.0$ & $9.8 \pm 1.9$ & $8.5 \pm 1.5$ & $7.8 \pm 2.3$ & $6.1 \pm 1.3$ \\
\hline WR $\%$ predicted & $125.9 \pm 24.4$ & $97.1 \pm 20.3^{*, \#}$ & $82.5 \pm 18.8^{*, \#}$ & $67.3 \pm 17.1^{*, \#}$ & $48.9 \pm 17.0^{*}$.\# \\
\hline$V^{\prime} 0_{2} \%$ predicted & $118.4 \pm 18.3$ & $91.9 \pm 23.5^{*, \#}$ & $78.4 \pm 22.7^{*, \#}$ & $60.9 \pm 17.5^{*, \#}$ & $40.8 \pm 11.5^{*, \#}$ \\
\hline$V^{\prime} E / M V V$ & $0.58 \pm 0.07$ & $0.73 \pm 0.10^{*}, \#$ & $0.88 \pm 0.07$ & $0.89 \pm 0.08$ & $0.92 \pm 0.10$ \\
\hline$V_{T} \mathrm{~L}$ & $1.90 \pm 0.42$ & $1.79 \pm 0.56^{*, \#}$ & $1.39 \pm 0.46^{*}, \#$ & $1.11 \pm 0.36^{*, \#}$ & $0.95 \pm 0.30 *$ *\# \\
\hline fR rpm & $38 \pm 10$ & $35 \pm 6^{*}$ & $34 \pm 9 *$ & $33 \pm 8 *$ & $25 \pm 6^{*, \#}$ \\
\hline EILV/TLC & $0.82 \pm 0.04$ & $0.86 \pm 0.06^{*, \#}$ & $0.91 \pm 0.05$ & $0.93 \pm 0.04$ & $0.95 \pm 0.03$ \\
\hline $\mathrm{PETCO}_{2} \mathrm{mmHg}$ & $31.6 \pm 3.8$ & $34.6 \pm 4.9^{*, \#}$ & $38.4 \pm 6.4^{*, \#}$ & $40.9 \pm 6.3^{*, \#}$ & $44.4 \pm 3.8^{* . \#}$ \\
\hline $\mathrm{SpO}_{2} \%$ & $95 \pm 3 *$ & $95 \pm 4^{*}$ & $93 \pm 4^{*}$ & $91 \pm 3^{*}$ & $89 \pm 3^{*}, \#$ \\
\hline Dyspnoea scores & $3(2)$ & $4(3)^{*}$ & $4(3)^{*}$ & $5(2)^{*, \#}$ & $5(3)^{*, \#}$ \\
\hline
\end{tabular}

Data are presented as $n$, mean \pm SDor median (interquartile range). WR: work rate; $V^{\prime} \mathrm{O}_{2}$ : oxygen production; $V^{\prime} E$ : minute ventilation; MVV: maximal voluntary ventilation: $V T$ : tidal volume; fR: respiratory frequency; EILV: end-inspiratory lung volume; TLC: total lung capacity; $\mathrm{PETCO}_{2}$ : end-tidal carbon dioxide tension; $\mathrm{SpO}_{2}$ : arterial oxygen saturation measured by pulse oximetry. *: $p<0.05$ versus controls; ${ }^{\#}: p<0.05$ versus other GOLD stages. 

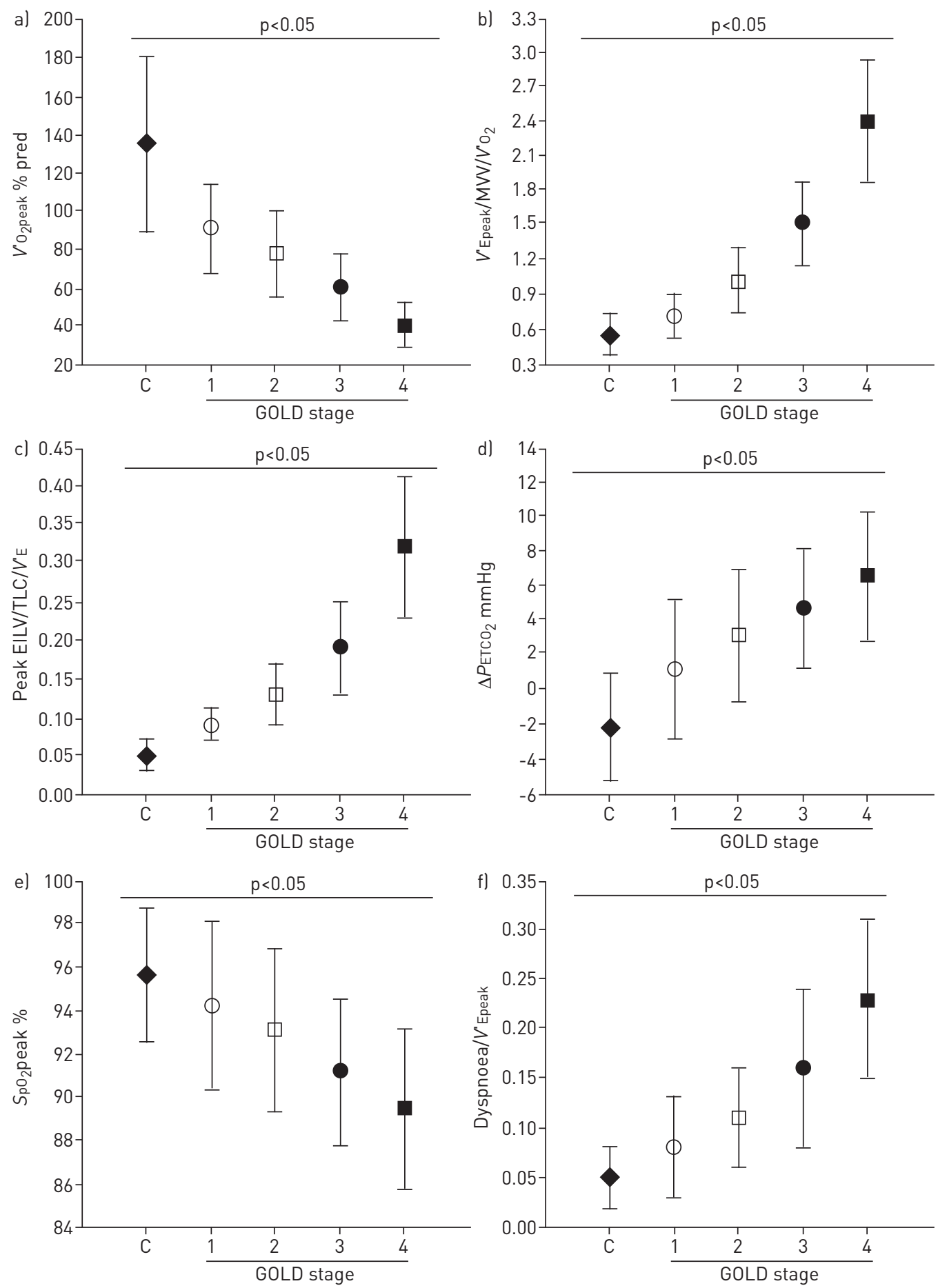

FIGURE 2 Selected physiological and subjective responses to exercise in chronic obstructive pulmonary disease patients according to Global Initiative for Chronic Obstructive Lung Disease (GOLD) stages and healthy controls $(\mathrm{C}) . V^{\prime} \mathrm{O}_{2}$ peak: peak oxygen uptake; $V^{\prime}$ Epeak: peak minute ventilation; MVV: maximal voluntary ventilation; EILV: end-inspiratory lung volume; TLC: total lung capacity; $\triangle P \mathrm{ETCO}_{2}$ : exercise-rest change in end-tidal carbon dioxide tension; $\mathrm{PpO}_{2}$ peak: peak arterial oxygen saturation measured by pulse oximetry.

Nadirs were greater than slopes in the great majority of subjects (96.8\%) (fig. 5b). Nadir values were reached at peak exercise in all patients from GOLD stages 3 and 4, and in the majority of those in GOLD stages 1 and 2 (74.5\% and 87.3\%, respectively) (fig. 3). Significant correlations between nadir versus intercept and slope were found only in controls and GOLD stage 1 patients ( $\mathrm{r}=0.61$ and 0.59 , respectively, $\mathrm{p}<0.05)$. As depicted in figure $4 \mathrm{c}$ nadirs were increased to a similar extent in all patient groups compared 

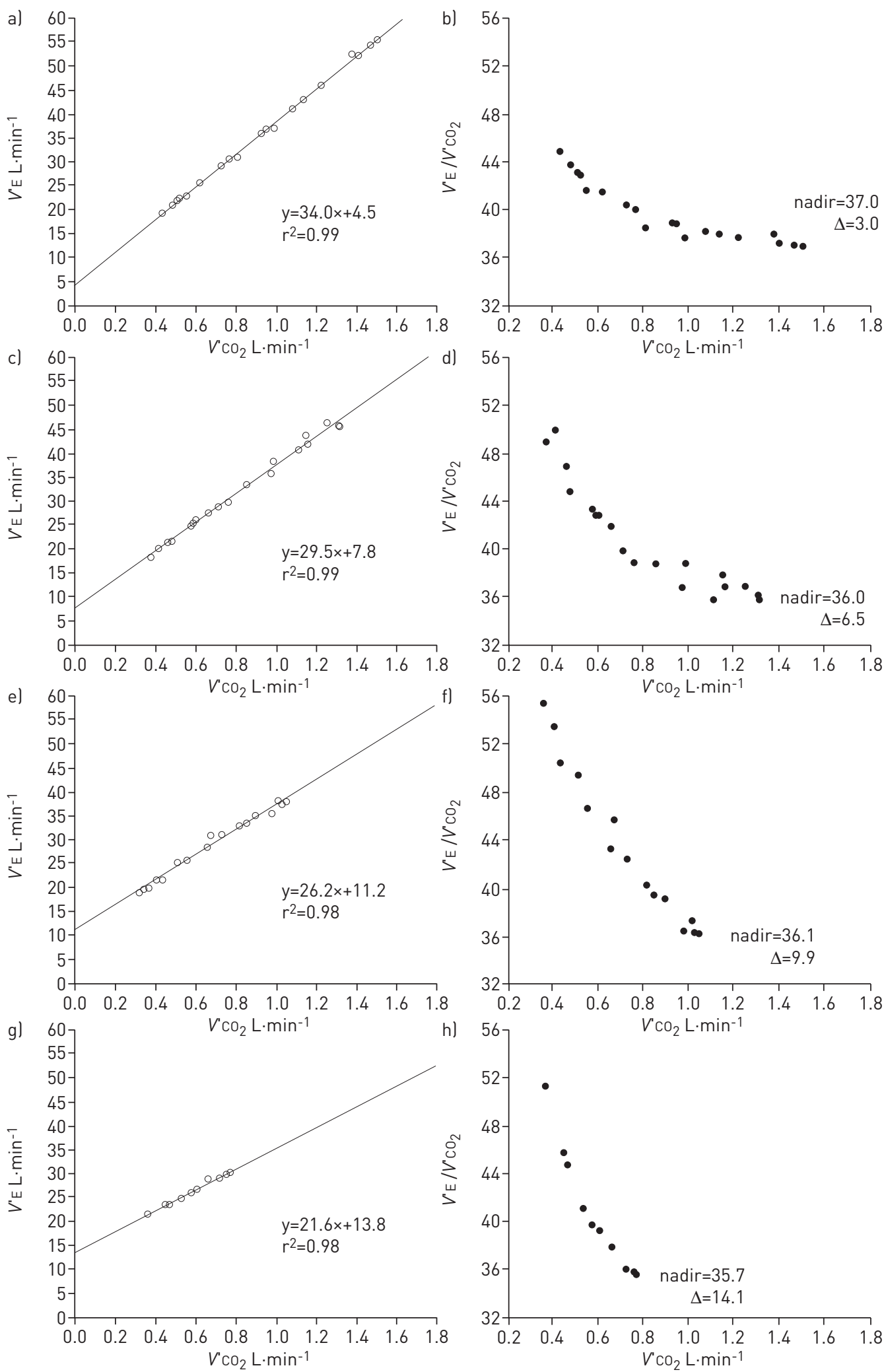

FIGURE 3 Response profiles for linear minute ventilation $\left(V^{\prime} \mathrm{E}\right)$ carbon dioxide production $\left(V^{\prime} \mathrm{CO}_{2}\right)$ relationship (a, c, e and $\mathrm{g}$ ) and $V^{\prime} \mathrm{E} / V^{\prime} \mathrm{CO}_{2}$ ratio (b, d, $\mathrm{f}$ and $\mathrm{h}$ ) during incremental exercise, in representative Global Initiative in Chronic Obstructive Lung Disease stage 1 ( $\mathrm{a}$ and b), stage 2 ( $\mathrm{c}$ and $\mathrm{d}$ ), stage 3 (e and $\mathrm{f}$ ), and stage 4 ( $\mathrm{g}$ and $\mathrm{h}$ ). Each data point is an arithmetic mean of breath-to-breath values recorded over a 30-s time period. Nadir: $V^{\prime} \mathrm{E} / V^{\prime} \mathrm{CO}_{2}$ nadir; $\Delta$ : nadirslope difference. 
$a$

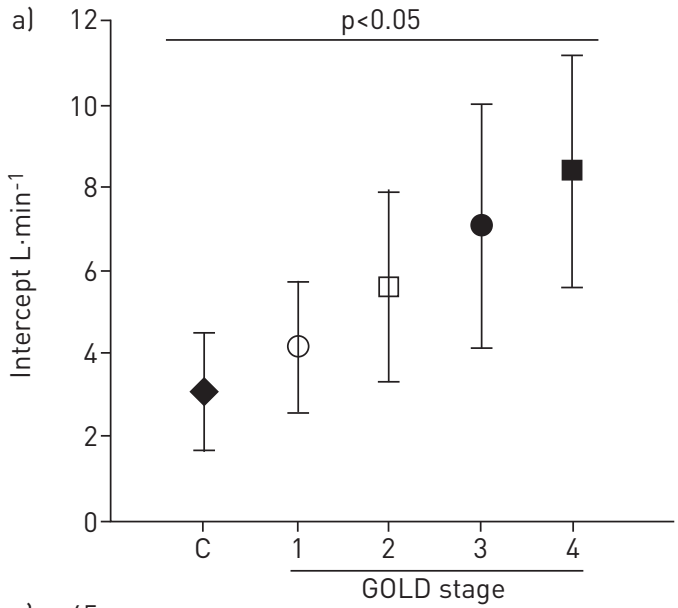

c)

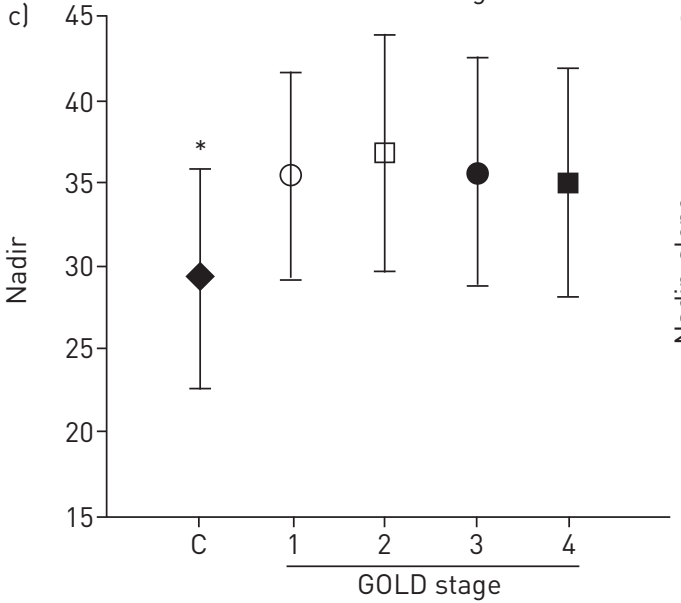

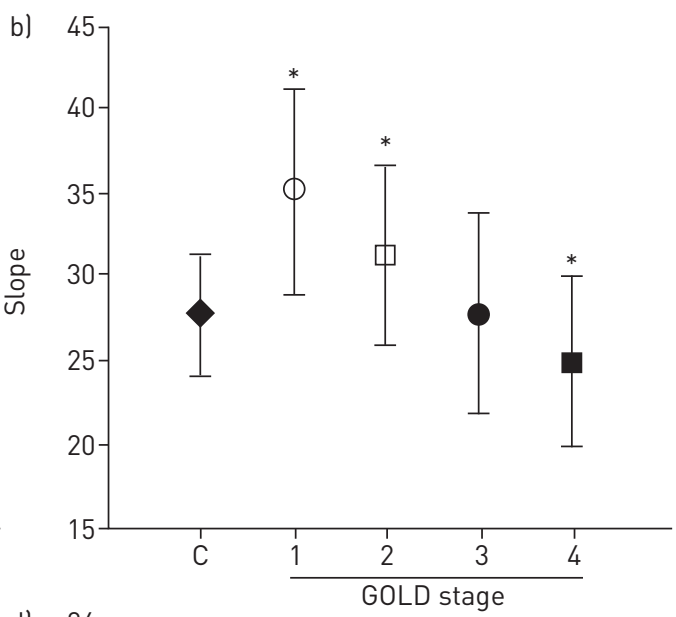

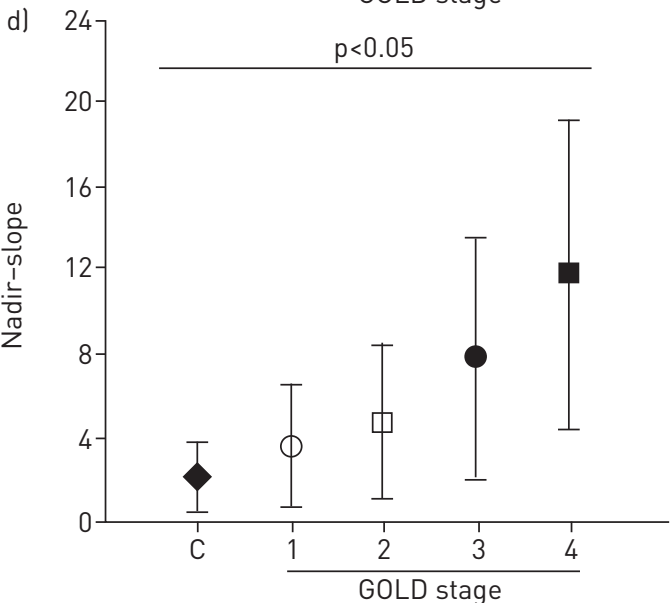

FIGURE 4 Measures of ventilatory inefficiency in chronic obstructive pulmonary disease patients according to Global Initiative for Chronic Obstructive Lung Disease (GOLD) stages and healthy controls (C). ${ }^{*}$ : $<<0.05$ different from controls.

to controls. As expected from similar nadirs and progressively lower slopes, nadir-slope differences markedly increased from GOLD stages 1 to 4 (figs $4 \mathrm{~d}$ and $5 \mathrm{~b}$ ). Despite a significant positive association between intercept and nadir-slope differences, the scatter around the correlation line increased at higher values (fig. 5b).

a)

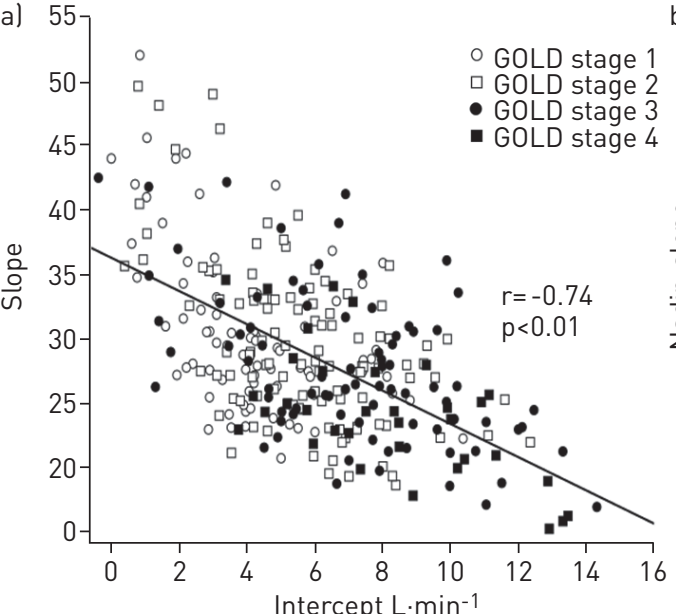

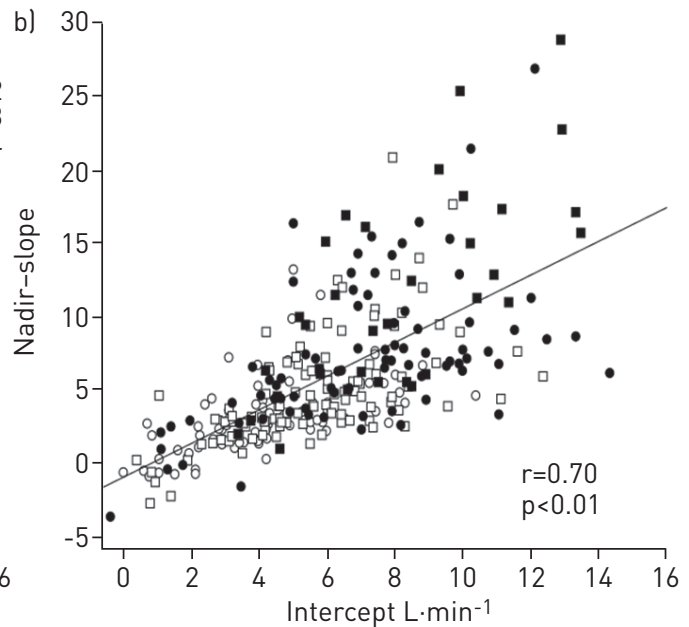

FIGURE 5 Significant correlations between a) intercept versus slope and b) intercept versus nadir-slope differences. GOLD: Global Initiative for Chronic Obstructive Lung Disease. 

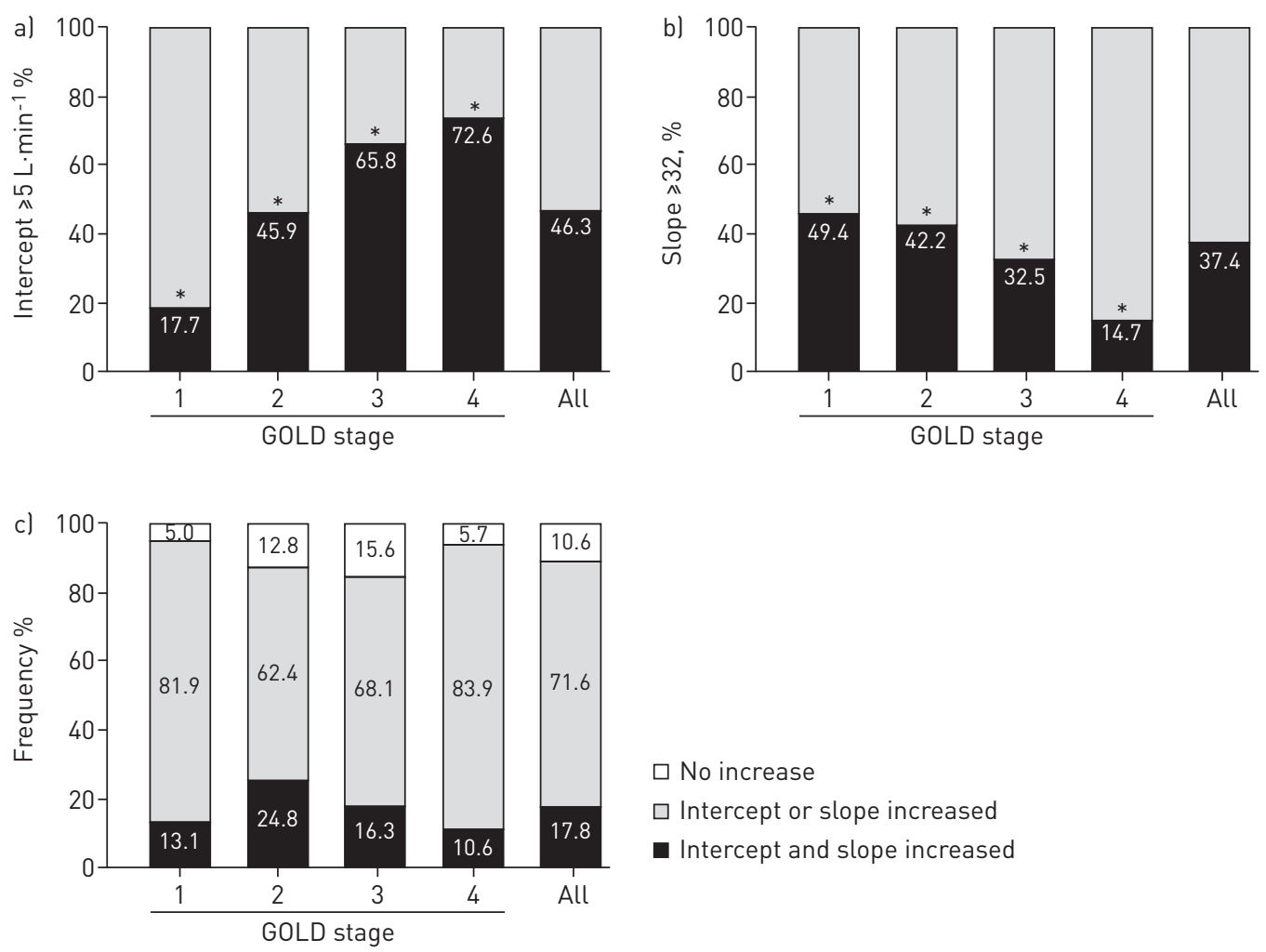

FIGURE 6 Relative frequency of patients with a) intercepts and b) slopes $>95 \%$ upper confidence limit found in controls ( $>5 \mathrm{~L} \cdot \mathrm{min}^{-1}$ and $>32$, respectively) in chronic obstructive pulmonary disease patients according to Global Initiative for Chronic Obstructive Lung Disease (GOLD) stages. c) The frequency of patients in whom either none or both measures of ventilatory inefficiency were greater than these cut-offs.

\section{Functional and subjective correlates of ventilatory inefficiency}

The putative relationships between different measures of ventilatory inefficiency and clinically relevant outcomes were assessed in patients separated by COPD severity. Increases in intercept, slope and nadir were all similarly related to lower DLCO ( $\mathrm{r}=-0.62,0.64$ and -0.61 , respectively), lower $V^{\prime} \mathrm{O}_{2}$ peak $(\mathrm{r}=-0.58,0.50$ and -0.53$)$ and greater dyspnoea $/ V^{\prime} \mathrm{E}$ ratios $(\mathrm{r}=0.65,-0.63$, and 0.60 , respectively) in GOLD stage 1 patients $(\mathrm{p}<0.01)$. Interestingly, all ventilatory inefficiency parameters were better related to dyspnoea scores than FEV $1(r=0.18, p>0.05)$ in this group. Higher dyspnoea/ $V^{\prime}$ Eratio scores were found in those with slopes $>32$ compared to their counterparts $\left(0.14 \pm 0.03\right.$ versus $0.08 \pm 0.04$ Borg score units $\left.\cdot \mathrm{L}^{-1} \cdot \mathrm{min}^{-1}\right)(\mathrm{p}<0.01)$.

Increases in intercepts related consistently better to DLCO and $V^{\prime} \mathrm{O}_{2}$ peak than decreases in slope in GOLD stages $2-4$ patients $(r=-0.69$ versus 0.42 in GOLD stage $2, r=-0.72$ versus 0.45 in GOLD stage 3 , and $\mathrm{r}=-0.70$ versus 0.38 in GOLD stage $4 ; \mathrm{p}<0.01$ for intercept and $\mathrm{p}<0.05$ for slope correlations). Particularly high dyspnoea/ $V^{\prime}$ Eratio scores were found in those with very high intercepts $\left(>8 \mathrm{~L} \cdot \mathrm{min}^{-1}\right)$ and pronouncedly shallow slopes $(<24)$ compared to their counterparts $(0.28 \pm 0.08$ versus $0.14 \pm 0.07$ Borg score units.L. $\left.\mathrm{min}^{-1}\right)(\mathrm{p}<0.01)$. Similar results were found in relation to pulmonary gas exchange impairment (peak-rest decreases in $\mathrm{SpO}_{2}$ and increases in $\left.\mathrm{PETCO}_{2}\right)$ and mechanical ventilatory constraints (higher $\left(V^{\prime} \mathrm{E} /\right.$ $\mathrm{MVV}) / V^{\prime} \mathrm{O}_{2}$ and (EILV/TLC) $\left./ V^{\prime} \mathrm{E}\right) ; \mathrm{r}$ values ranged from 0.62 to 0.73 for the intercept $(\mathrm{p}<0.01)$ and from -0.48 to -0.60 for the slope $(\mathrm{p}<0.05)$. There were no significant correlations between nadir and any of these variables in GOLD stages 2-4. Conversely, only the nadir was related to exercise-test duration across the whole sample $(\mathrm{r}=-0.63, \mathrm{p}<0.01)$.

\section{Discussion}

This is the first study to systematically investigate the effect of COPD severity on measures of exercise ventilatory inefficiency (intercept, slope and nadir) in a large sample of males and females with mild to end-stage disease. Our main results can be summarised as follow: 1) significant ventilatory inefficiency was found in mild, GOLD stage 1, COPD patients when compared to controls, a finding related to exertional breathlessness and poorer exercise capacity; 2) higher ventilation intercepts and, to a less extent, lower slopes related to greater mechanical constraints, worsening pulmonary gas exchange, higher dyspnoea scores and exercise intolerance; and 3) changes in the nadir, however, failed to predict those abnormalities 
in GOLD stages 2-4. These results indicate that exercise ventilatory inefficiency is a physiological marker related to clinically relevant end-points in mild to end-stage COPD. A hitherto neglected variable, the $V^{\prime} \mathrm{E}-V^{\prime} \mathrm{CO}_{2}$ intercept [1], emerged as a particularly useful index for ventilatory inefficiency, across the continuum of COPD severity.

There has been renewed interest in exercise ventilatory inefficiency as a physiological marker in patients with COPD [9-19]. However, it is rather surprising that no previous study has systematically looked at this topic in a sufficiently large number of patients with varied degrees of disease severity. In fact, some smaller studies evaluated patients with advanced emphysema [9] or mid-stage disease [22, 23]. The largest previous study did not evaluate GOLD stage 1 patients and restricted its analysis to $V^{\prime} \mathrm{E}-V^{\prime} \mathrm{CO}_{2}$ peak [10]. Therefore, the prevailing view on the topic remains largely influenced by the cardiovascular literature, i.e. high $V^{\prime} \mathrm{E}-V^{\prime} \mathrm{CO}_{2}$ slope and $V^{\prime} \mathrm{E} / V^{\prime} \mathrm{CO}_{2}$ nadir indicate worsening ventilatory inefficiency, regardless of COPD severity $[9,10,21,26]$.

However, our main results demonstrate that this approach is likely to lead to substantial misinterpretation of ventilatory inefficiency in COPD. Apart from GOLD stage 1 patients in whom both slope and nadir were higher, compared to controls, our results would indicate a paradoxical "improvement" (slope) or an apparent stability (nadir) in ventilatory inefficiency in GOLD stages 2-4 (fig. $4 \mathrm{~b}$ and c). However, lower $V^{\prime} \mathrm{E}-V^{\prime} \mathrm{CO}_{2}$ slopes in more advanced disease, were explained by worsening mechanical constraints (fig. 2c) $[9,23]$ and, probably, an increase in carbon dioxide set-point [29]. Similar $V^{\prime} \mathrm{E} / V^{\prime} \mathrm{CO}_{2}$ nadirs across patient groups (fig. 4c) reflected the opposite changes in $V^{\prime} \mathrm{E}-V^{\prime} \mathrm{CO}_{2}$ slope and intercept (figs $5 \mathrm{a}$ and $6 \mathrm{c}$ ) and shorter test durations in more severe patients.

In contrast, we found that the expected increase in "wasted" ventilation as COPD evolved from GOLD stage 1 to 4 [20] was better reflected by progressive increases in intercept (fig. 4a). This interpretation is in line with some $[25,30]$, but not all $[31,32]$, experimental studies in normal subjects, in which increases in series (anatomical) $V \mathrm{D}$ upshifted the $V^{\prime} \mathrm{E}-V^{\prime} \mathrm{CO}_{2}$ relationship, and $\mathrm{PETCO}_{2}$, with no appreciable change in slope. As pointed out by GARGulio et al. [25], $V^{\prime} \mathrm{E}$ in the absence of pulmonary gas exchange (i.e. $V^{\prime} \mathrm{E}$ intercept with null $V^{\prime} \mathrm{CO}_{2}$ ) theoretically equals to $V \mathrm{D}$. In fact, resting $V^{\prime} \mathrm{E}$, the closest biologically plausible correlate of the intercept, does shift upwards as COPD progresses, a finding that is likely to reflect the worsening of ventilation-perfusion mismatch [20]. The key limitation of the $V^{\prime} \mathrm{E}-V^{\prime} \mathrm{CO}_{2}$ intercept, to constitute a mathematical extrapolation, is paradoxically its main advantage in COPD; by definition, the intercept cannot be constrained by dynamic mechanics (as the slope) or test duration (as the nadir). We interpret the overlap of intercept values among GOLD stages (fig. 4a) as a reflection of FEV1 being a poor predictor of the ventilatory response in individual patients [20]. For instance, the ventilatory drive in COPD is variably influenced by afferent information from the working limbs [33] and peripheral chemoreceptors [16] at a given FEV1.

It is also noteworthy that $V^{\prime} \mathrm{E} / V^{\prime} \mathrm{CO}_{2}$ nadir exceeds the slope to a greater extent if the subjects stop exercising "prematurely" $[4,6,26]$, e.g. due to limiting dyspnoea. In fact, we found an inverse relationship between nadir and test duration in patients. Moreover, the nadir-slope differences not equal to the intercept, particularly in more advanced COPD (fig. 5b). These data indicate that too short a test resulted in $V^{\prime} \mathrm{E} / V^{\prime} \mathrm{CO}_{2}$ nadir overestimating the slope in these patients. Of note, nadir-slope difference may decrease after beneficial interventions, if higher exercise tolerance (leading to lower nadir in more severe patients) is associated with improved ventilatory response (higher slope). Prospective trials are warranted to assess the usefulness of nadir-slope difference as an outcome in COPD.

The present results hold other important clinical implications for the interpretation of the $V^{\prime} \mathrm{E}-V^{\prime} \mathrm{CO}_{2}$ relationship in COPD. First and foremost, it is rather remarkable that GOLD stage 1 patients, with largely preserved $\mathrm{FEV} 1$, showed significant impairment in exercise ventilatory efficiency, a finding closely related to exertional breathlessness. These data suggest that ventilatory inefficiency might constitute a useful physiological marker of disease severity in this subpopulation [11]. It is also conceivable that GOLD stages 2-4 patients, showing high intercepts and lower slopes, are at greater risk of a negative outcome. However, some patients with pulmonary artery pressure values greater than expected by the degree of hypoxaemia [14, 15], do present with high slopes; for these patients, such findings may still represent a negative prognostic marker. Similar considerations apply to directional changes induced by interventions aimed at decreasing $V_{\mathrm{D}} / V_{\mathrm{T}}[16,18,19]$. Slope, intercept and nadir are all expected to decrease in GOLD stage 1 patients. However, if the ventilatory constraints are also alleviated by the intervention, lower intercepts and higher slopes can be anticipated in more severe patients. Highly variable, and even neutral, effects may occur in the nadir. Another clinical application of the intercept relates to its potential to suggest COPD in heart failure patients and vice versa [24]. For instance, null or negative intercept values, a not so infrequent finding in heart failure $[13,24]$, were found in $<1 \%$ of our patients (fig. 5). Whether higher intercepts and slower slopes in patients with coexistent COPD would 
impact in the prognostic relevance of ventilatory inefficiency in heart failure [7], deserves further investigation. Finally, the controversy on nadir or $V^{\prime} \mathrm{E}-V^{\prime} \mathrm{CO}_{2}$ peak being the preferred measure of ventilatory inefficiency $[7,21,26]$ is not clinically pertinent to COPD as these variables differ in only a minority of less severe patients.

The present study has, naturally, some limitations. As a noninvasive, clinical physiology study, involving a large number of patients, our mechanistic extrapolations are necessarily limited [34, 35]. For instance, it remains speculative whether dynamic decreases in carbon dioxide set-point and/or increases in physiological $V \mathrm{D} / V \mathrm{~T}$ would steepen the slope in particular patients [25]. However, the calculation of changes in $V \mathrm{D} / V \mathrm{~T}$ during rapidly progressive exercise is, notoriously, inaccurate, particularly in COPD [36]. In the absence of a true criterion test for exercise ventilatory inefficiency, we relied on a cluster of variables that are indirect markers of pulmonary gas-exchange disturbances. In this context, exercise induced elevations in $\mathrm{PETCO}_{2}$ reflect either true carbon dioxide retention or delayed lung emptying in COPD $[37,38]$. Considering that $\mathrm{PETCO}_{2}$ grossly underestimates alveolar carbon dioxide tension in these patients [36], our assumptions, which are increases in $\mathrm{PETCO}_{2}$ indicate more severe gas exchange disturbances in COPD, still hold true. It should be noted that we might have underestimated the role of hypoxaemia in modulating ventilatory inefficiency, as we did not evaluate overtly hypoxaemic patients. We also recognise that the modulating effects of disease phenotypes (particularly emphysema) [9] and test modality [39], on the different strategies to express ventilatory inefficiency, require better characterisation in COPD.

In conclusion, a hitherto neglected variable, the $V^{\prime} \mathrm{E}-V^{\prime} \mathrm{CO}_{2}$ intercept [1], better expressed the progressive worsening on exercise ventilatory inefficiency across the continuum of COPD severity (GOLD stages 1-4). Compared to commonly used measures, i.e. slope and nadir, the intercept correlated better with key outcomes of clinical relevance, i.e. dyspnoea and exercise tolerance, regardless of the stage of disease. High intercepts in patients with largely preserved spirometry (GOLD stage 1), suggest coexistent ventilation-perfusion abnormalities that may explain persistent symptoms (dyspnoea and activity restriction) and may prompt further investigations. This variable may, therefore, assist in clinical phenotyping and deserves to be prospectively tested as a prognostic index in longitudinal studies and a physiological end-point in interventional trials in COPD patients.

\section{References}

Whipp BJ, Ward SA. Cardiopulmonary coupling during exercise. J Exp Biol 1982; 100: 175-193.

2 Whipp BJ, Ward SA. The coupling of ventilation to pulmonary gas exchange during exercise. In: Whipp BJ, Wasserman K., eds. Pulmonary Physiology and Pathophysiology of Exercise. New York, Dekker, 1991: pp. 271-307.

3 Wasserman K, Casaburi R. Acid-base regulation during exercise in humans. In: Whipp B.J. Wasserman K, eds. Pulmonary Physiology and Pathophysiology of Exercise. New York, Dekker, 1991; pp. 405-448.

4 Whipp BJ. The control of exercise hyperpnea. In: Hornbein T, ed. The Regulation of Breathing. Dekker, New York, 1981; pp. 1069-1139.

5 Whipp BJ. Control of the exercise hyperpnea: the unanswered question. Adv Exp Med Biol 2008; 605: 16-21.

6 Whipp BJ, Ward SA, Wasserman K. Ventilatory responses to exercise and their control in man. Am Rev Respir Dis 1984; 129: S17-S20.210.

7 Sue DY. Excess ventilation during exercise and prognosis in chronic heart failure. Am J Respir Crit Care Med 2011; 183: $1302-1310$.

8 Ferreira EV, Ota-Arakaki JS, Ramos RP, et al. Optimizing the evaluation of excess exercise ventilation for prognosis assessment in pulmonary arterial hypertension. Eur J Prev Cardiol 2014; 21: 1409-1419.

9 Paoletti P, De Filippis F, et al. Cardiopulmonary exercise testing (CPET) in pulmonary emphysema. Respir Physiol Neurobiol 2011; 179: 167-173.

10 Thirapatarapong W, Armstrong HF, Thomashow BM, et al. Differences in gas exchange between severities of chronic obstructive pulmonary disease. Respir Physiol Neurobiol 2013; 186: 81-86.

11 Chin RC, Guenette JA, Cheng S, et al. Does the respiratory system limit exercise in mild chronic obstructive pulmonary disease? Am J Respir Crit Care Med 2013; 187: 1315-1323.

12 Thirapatarapong W, Armstrong HF, Bartels MN. Comparison of cardiopulmonary exercise testing variables in COPD patients with and without coronary artery disease. Heart Lung 2014; 43: 146-151.

13 Guazzi M, Myers J, Vicenzi M, et al. Cardiopulmonary exercise testing characteristics in heart failure patients with and without concomitant chronic obstructive pulmonary disease. Am Heart J 2010; 160: 900-905.

14 Holverda S, Bogaard HJ, Groepenhoff $\mathrm{H}$, et al. Cardiopulmonary exercise test characteristics in patients with chronic obstructive pulmonary disease and associated pulmonary hypertension. Respiration 2008; 76: 160-167.

15 Vonbank K, Funk GC, Marzluf B, et al. Abnormal pulmonary arterial pressure limits exercise capacity in patients with COPD. Wien Klin Wochenschr 2008; 120: 749-755.

16 Peters MM, Webb KA, O'Donnell DE. Combined physiological effects of bronchodilators and hyperoxia on exertional dyspnoea in normoxic COPD. Thorax 2006; 61: 559-567.

17 Torchio R, Guglielmo M, Giardino R, et al. Exercise ventilatory inefficiency and mortality in patients with chronic obstructive pulmonary disease undergoing surgery for non-small cell lung cancer. Eur J Cardiothorac Surg 2010; 38: 14919.

18 Habedank D, Ewert R, Hummel M, et al. The effects of bilateral lung transplantation on ventilatory efficiency, oxygen uptake and the right heart: a two-yr follow-up. Clin Transplant 11;25: E38-E45. 
19 Kim V, Kretschman DM, Sternberg AL, et al. Weight gain after lung reduction surgery is related to improved lung function and ventilatory efficiency. Am J Respir Crit Care Med 2012; 186: 1109-1116.

20 O'Donnell DE, Laveneziana $\mathrm{P}$, Webb $\mathrm{K}$, et al. Chronic obstructive pulmonary disease: clinical integrative physiology. Clin Chest Med 2014; 35: 51-69.

21 Sun XG, Hansen JE, Garatachea N, et al. Ventilatory efficiency during exercise in healthy subjects. Am J Respir Crit Care Med 2002; 166: 1443-1448.

22 Caviedes IR, Delgado I, Soto R. Ventilatory inefficiency as a limiting factor for exercise in patients with COPD. Respir Care 2012; 57: 583-589.

23 Teopompi E, Tzani P, Aiello M, et al. Excess ventilation and ventilatory constraints during exercise in patients with chronic obstructive pulmonary disease. Respir Physiol Neurobiol 2014; 197: 9-14.

24 Teopompi E, Tzani P, Aiello M, et al. Ventilatory response to carbon dioxide output in subjects with congestive heart failure and in patients with COPD with comparable exercise capacity. Respir Care 2014; 59: 1034-1041.

25 Gargiulo P, Apostolo A, Perrone-Filardi P, et al. A non invasive estimate of dead space ventilation from exercise measurements. PLoS One 2014; 9: e87395.

26 Neder JA, Nery LE, Peres C, et al. Reference values for dynamic responses to incremental cycle ergometry in males and females aged 20 to 80. Am J Respir Crit Care Med 2001; 164: 1481-1486.

27 Global Initiative for Chronic Obstructive Lung Disease. Global Strategy for the Diagnosis, Management, and Prevention of Chronic Obstructive Lung Disease Updated 2014. www.goldcopd.org/guidelines-globalstrategy-for-diagnosis-management.html Date last accessed: July 23, 2014. Date last updated: January 2014.

28 Borg GA. Psychophysical bases of perceived exertion. Med Sci Sports Exerc 1982; 14: 377-381.

29 Oren A, Wasserman K, Davis JA, et al. Effect of $\mathrm{CO}_{2}$ set point on ventilatory response to exercise. J Appl Physiol Respir Environ Exerc Physiol 1981; 51: 185-189.

30 Jensen D, O'Donnell DE, Li R, et al. Effects of dead space loading on neuro-muscular and neuro-ventilatory coupling of the respiratory system during exercise in healthy adults: implications for dyspnea and exercise tolerance. Respir Physiol Neurobiol 2011; 179: 219-226.

31 Ward SA, Whipp BJ. Ventilatory control during exercise with increased external dead space. J Appl Physiol Respir Environ Exerc Physiol 1980; 48: 225-231.

32 Poon CS. Potentiation of exercise ventilatory response by airway $\mathrm{CO}_{2}$ and dead space loading. J Appl Physiol 1992; 73: 591-595.

33 Gagnon P, Bussières JS, Ribeiro F, et al. Influences of spinal anesthesia on exercise tolerance in patients with chronic obstructive pulmonary disease. Am J Respir Crit Care Med 2012; 186: 606-615.

34 Poon CS, Tin C. Mechanism of augmented exercise hyperpnea in chronic heart failure and dead space loading. Respir Physiol Neurobiol 2013; 186: 114-130.

35 Ward SA. Commentary on "Mechanism of augmented exercise hyperpnea in chronic heart failure and dead space loading" by Poon and Tin. Respir Physiol Neurobiol 2013; 189: 203-210.

36 Lewis DA, Sietsema KE, Casaburi R, et al. Inaccuracy of noninvasive estimates of VD/VT in clinical exercise testing. Chest 1994; 106: 1476-1480.

37 Yamanaka MK, Sue DY. Comparison of arterial-end-tidal $\mathrm{PCO}_{2}$ difference and dead space/tidal volume ratio in respiratory failure. Chest 1987; 92: 832-835.

38 Steinacker JM, Dehnert C, Whipp BJ. Effect of exercise intensity on the changes in alveolar slopes of carbon dioxide and oxygen expiratory profiles in humans. Eur J Appl Physiol 2001; 85: 56-61.

39 Palange $\mathrm{P}$, Forte $\mathrm{S}$, Onorati $\mathrm{P}$, et al. Ventilatory and metabolic adaptations to walking and cycling in patients with COPD. J Appl Physiol 2000; 88: 1715-1720. 